\title{
Increasing complexity: which drug class to choose for treatment of hypertension in the elderly?
}

\author{
This article was published in the following Dove Press journal: \\ Clinical Interventions in Aging \\ 24 March 2014 \\ Number of times this article has been viewed
}

\author{
Edelgard Anna Kaiser' \\ Ulrich Lotze ${ }^{2}$ \\ Hans Hendrik Schäfer ${ }^{1,3}$ \\ 'Roche Diagnostics International \\ AG, Rotkreuz, Switzerland; \\ 2Department of Internal Medicine, \\ DRK-Manniske-Krankenhaus Bad \\ Frankenhausen, Bad Frankenhausen, \\ Germany; ${ }^{3}$ Institute of Anatomy II, \\ University Hospital Jena, Friedrich- \\ Schiller University, Jena, Germany
}

Correspondence: Hans Hendrik Schäfer Roche Diagnostics International AG, Forrenstrasse 2, Rotkreuz 6346

Zug, Switzerland

Tel +4 I 4I 79923 I 5

Fax +4| 4| 7927228

Email hendrik.schaefer@roche.com

\begin{abstract}
Treatment of hypertension in the elderly is expected to become more complex in the coming decades. Based on the current landscape of clinical trials, guideline recommendations remain inconclusive. The present review discusses the latest evidence derived from studies available in 2013 and investigates optimal blood pressure (BP) and preferred treatment substances. Three common archetypes are discussed that hamper the treatment of hypertension in the very elderly. In addition, this paper presents the current recommendations of the NICE 2011, JNC7 2013-update, ESH/ESC 2013, CHEP 2013, JNC8 and ASH/ISH guidelines for elderly patients. Advantages of the six main substance classes, namely diuretics, beta-blockers (BBs), calcium channel blockers (CCBs), angiotensin-converting enzyme inhibitors (ACEIs), angiotensin receptor blockers (ARBs), and direct renin inhibitors (DRIs) are discussed. Medical and economic implications of drug administration in the very elderly are presented. Avoidance of treatment-related adverse effects has become increasingly relevant. Current substance classes are equally effective, with similar effects on cardiovascular outcomes. Selection of substances should therefore also be based on collateral advantages of drugs that extend beyond BP reduction. The combination of ACEIs and diuretics appears to be favorable in managing systolic/diastolic hypertension. Diuretics are a preferred and cheap combination drug, and the combination with $\mathrm{CCBs}$ is recommended for patients with isolated systolic hypertension. ACEIs and CCBs are favorable for patients with dementia, while CCBs and ARBs imply substantial cost savings due to high adherence.
\end{abstract}

Keywords: drug, antihypertensive therapy, elderly, very elderly, guidelines, evidence

\section{Introduction}

In the last decade, life expectancy has increased remarkably in affluent Western societies. ${ }^{1}$ In the USA, approximately 39 million people (13\% of the population) were aged $\geq 65$ years in 2008 and this number is expected to increase to 72 million $(20 \%$ of the population) in $2030 .^{2}$ In the European Union, over $30 \%$ of the population will be older than 65 years by 2060 , and in Germany octogenarians will account for $14 \%$ of the population in $2060 .^{3,4}$ In patients $>65$ years of age, $78 \%$ of older women and $64 \%$ of older men have either diagnosed or undiagnosed hypertension. Based on the age-dependent blood pressure (BP) targets currently recommended by the ESH/ESC (European Society of Hypertension/European Society of Cardiology) guidelines, ${ }^{5}$ it is appropriate to differentiate between the "elderly" and the "very elderly" in this review. The "elderly" comprises the group of patients aged $\geq 65$ years. Patients 80 years and older are considered "very elderly" as described by Gueyffier et al for the Individual 
Data Analyses Antihypertensive Intervention (INDANA) group ${ }^{6}$ and in the Hypertension in the Very Elderly Trial (HYVET). ${ }^{7}$

Due to improvements in diagnosis and treatment, long-term consequences of arterial hypertension have shifted towards the elderly/very elderly population, but treatment has become more difficult in the light of comorbidities. ${ }^{8}$ In addition, the tablet burden in octogenarians hampers adherence to medication, and diseases requiring intensified treatment have their highest occurrence in the very elderly. ${ }^{9}$ The following three archetypes characterize current challenges in high-age patient management.

1. Discrepancy between required evidence and investment in clinical trials: it is difficult to obtain reliable long-term data because the average life expectancy of patients included in clinical trials is shorter than the duration of these studies. Another problem is that generation of specific evidence in the elderly and very elderly is expensive, while the anticipated revenue for pharmaceutical companies is relatively low. Low evidence leads to guideline ambiguity, subjective treatment decisions, and low target blood pressure attainment (TBPA). ${ }^{10}$
2. Eroding goals in treatment: an increasing number of physicians believe in comfortable end-of-life-management with less aggressive treatment. ${ }^{11}$ In a 2002 survey, $25 \%$ of physicians believed that treatment of patients aged $\geq 85$ years implied more risks than benefits, ${ }^{12}$ and over $58 \%$ of physicians only initiate antihypertensive treatment when patients' systolic blood pressure (SBP) exceeds $160 \mathrm{mmHg}$. In a Spanish trial, physicians perceived uncontrolled BP in $44.1 \%$ of patients as being well controlled. ${ }^{13}$ This perception is possibly based on the fallacy that BP levels need to be higher in older patients because of atherosclerotic alterations of cerebral vessels.

3. Attractiveness principle in competing disease areas: polypharmacy in the very elderly is unfortunate because treatment gets prioritized according to the severity of comorbidities and side-effects. As hypertension does not usually affect patient quality of life, other treatments are often favored.

Figure 1 summarizes the challenges in antihypertensive treatment of the elderly and very elderly.

In the last couple of years, several revisions to international guidelines have been undertaken to establish the most

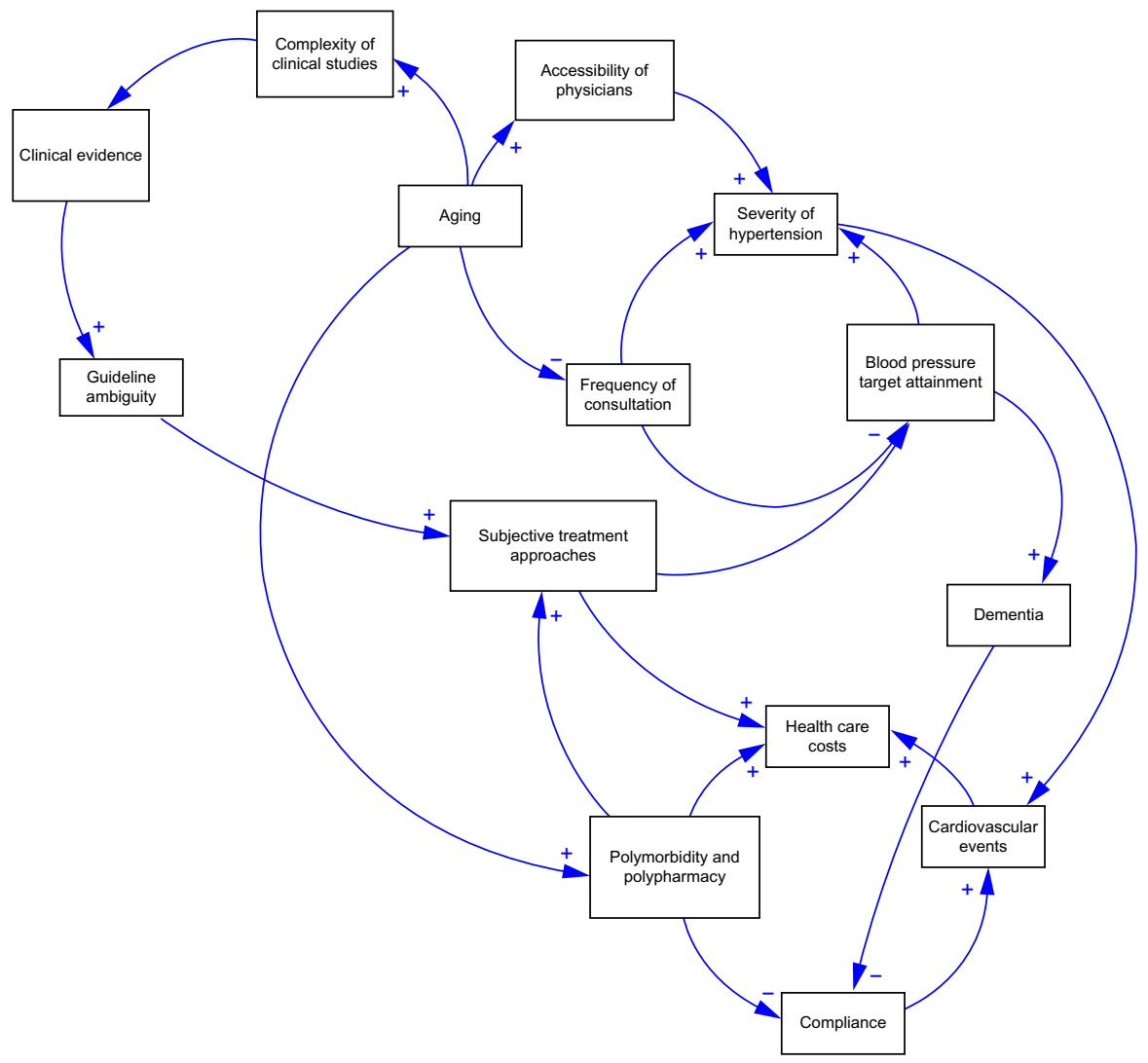

Figure I Model of the current problems of antihypertensive therapy in the elderly and very elderly. 
appropriate treatment by defining BP goals and recommended substances in the very elderly. Very recently the JNC (Joint National Committee) 8 guidelines ${ }^{14-18}$ and additionally ASH/ ISH (American Society of Hypertension/International Society of Hypertension) practical guidelines ${ }^{19}$ were released, with potentially more recommendation in collaboration with American Heart Association (AHA) and American College of Cardiology (ACC) to come by the end of 2014 or early 2015. ${ }^{20}$ The AHA, ACC, and Centers from Disease Control and Prevention (CDC) had just before published their "science advisory" on effective approaches for managing high blood pressure. ${ }^{21-23}$

The aims of the present review are as follows:

i. To present the latest evidence from trials with regard to optimal BP and preferred substances in 2013.

ii. To review the current recommendations of NICE (National Institute for Health and Clinical Excellence) $2011^{24}$ and the 2013 updates of the JNC7, ${ }^{25}$ ESH-ESC, ${ }^{5}$ CHEP (Canadian Hypertension Education Program), ${ }^{26}$ JNC8, ${ }^{14}$ and ASH/ISH practical guidelines. ${ }^{19}$

iii. To discuss advantages of the six main substance classes, namely diuretics, beta blockers (BBs), calcium channel blockers (CCBs), angiotensin-converting enzyme inhibitors (ACEIs), angiotensin receptor blockers (ARBs), and direct renin inhibitors (DRIs).

iv. To highlight medical and economic implications of drug administration in the very elderly.

\section{BP levels that establish the diagnosis of hypertension and set targets for therapy}

Lowering BP in a timely fashion has been shown to be beneficial with regard to cardiovascular outcome in hypertensive patients aged $\geq 67$ years. ${ }^{27} \mathrm{~A}$ recent meta-analysis comparing treatment and placebo groups showed intergroup BP reductions of 27.3/11.1 $\mathrm{mmHg}^{28}$ and significant reductions in all-cause death, cardiovascular death, stroke, and heart failure in patients aged $\geq 65$. Thus, BP lowering is a simple and therapy-independent concept to lower cardiovascular risk. $^{5,29}$ However, controversy remains regarding when to initiate treatment and what the optimal treatment goals are for this population.

On the one hand, the HYVET landmark trial ${ }^{30}$ demonstrated substantial reduction in fatal and non-fatal stroke, all-cause mortality, and cardiovascular disease in octogenarians treated who had a sustained SBP $\leq 160 \mathrm{mmHg}$. On the other hand, another meta-analysis ${ }^{31}$ showed only reduction of stroke risk, cardiovascular events, and heart failure, while allcause mortality remained high. Even more surprisingly, all-cause mortality was lowest in trials with the least BP reductions and the lowest therapy intensity. The difference between the two analyses may derive from the fact that in frail, elderly subjects with a diversity of comorbidities the potential benefit of antihypertensive treatment may be blunted by competing risks. Also, the expected protective effect of BP lowering seems to become progressively smaller with increasing age. ${ }^{32}$ As the average age in the HYVET trial was 84 years, there are few data available for the very elderly. Despite this problem, the results of HYVET have been implemented in the new ESH/ESC guidelines: BP should be reduced in patients $>80$ years and with initial SBP $>160 \mathrm{mmHg}$ to values between $140 \mathrm{mmHg}$ and $150 \mathrm{mmHg}$, provided that octogenarians are in good physical and mental condition. In physically fit hypertensive patients $<80$ years old with $\mathrm{SBP}>140 \mathrm{mmHg}$, $\mathrm{BP}$ values $<140 \mathrm{mmHg}$ may be considered, but in the fragile elderly population SBP should be adapted to individual tolerability. If patients live to $>80$ years of age they should continue their antihypertensive treatment if well tolerated. The newly relased $\mathrm{JNC}^{14,15}$ guidelines are mostly in line with the ESH/ESC guidelines. In patients $\geq 60$ years, JNC8 recommends lowering BP below 150/90 $\mathrm{mmHg}$. In the ASH/ ISH guidelines, ${ }^{19,20}$ age thresholds of $\mathrm{BP} \geq 150 / 90 \mathrm{mmHg}$ apply to patients $\geq 80$ years. With regard to the ASH/ISH guidelines, the scientific community argues that they were not developed according to the guideline process and thus should rather be considered as an "opinion piece". ${ }^{20}$ In general, BP target recommendations should mitigate any effect potentially associated with the "J-curve effect" discussed by Banach and Aronow. ${ }^{33}$

Recent late-outcome trials with more aggressive BP control have observed the J-curve effect in hypertensive patients, in patients with coronary artery disease, diabetes mellitus and left ventricular hypertrophy, and in elderly patients. ${ }^{34}$ When BP was lowered below a specific nadir, risk of coronary events (but not stroke) increased. Lowering diastolic BP (DBP) can lead to a critically reduced perfusion of the coronary arteries during the diastolic phase of the cardiac cycle. In healthy subjects, coronary pressure autoregulation provides a relatively constant perfusion to the myocardium over a fairly wide perfusion pressure ranging from $45 \mathrm{mmHg}$ to $125 \mathrm{mmHg}$. In patients with coronary heart disease, hypertension, and left ventricular hypertrophy, the autoregulation is no longer functional and the fractional flow reserve will be compromised and may lead to myocardial ischemia and myocardial infarction. ${ }^{35}$ The human brain is the organ that depends mostly on SBP. Cerebral blood flow autoregulation can operate at a mean arterial pressure between $60 \mathrm{mmHg}$ 
and $150 \mathrm{mmHg}$. Still, it seems that the heart is more vulnerable to BP changes than the brain, which has a much wider $\mathrm{BP}$ autoregulatory range.

In a secondary analysis of the INVEST (the INternational VErapamil SR/Trandolapril STudy) trial, ${ }^{36}$ hypertensive patients ( $\geq 50$ years of age) with coronary artery disease were treated with two different regimens. Grouped in 10-year increments, the adjusted hazard ratio for primary outcomes (all-cause death, non-fatal myocardial infarction, or non-fatal stroke) revealed a J-shape relationship between treatment SBP and DBP. Although all age groups showed a J-shaped curve, there was a progressive increase in SBP with increasing age. In very old patients ( $\geq 80$ years) the systolic pressure hazard ratio nadir was $140 \mathrm{mmHg},{ }^{37}$ compared with the nadir of $110 \mathrm{mmHg}$ for patients $<60$ years. However, the hazard ratio nadir for DBP was only marginally lower for those $\geq 80$ years $(70 \mathrm{mmHg})$ than for their younger counterparts $(75$ $\mathrm{mmHg}$ ). Overall, the incidence of stroke was much less than myocardial infarction and correlated with low SBP, whereas the incidence of myocardial infarction was correlated with low DBP.

In a Japanese trial, PATE-Hypertension II (Practitioner's trial on the efficacy of antihypertensive treatment in elderly patients with hypertension II), excessive SBP reduction to less than $120 \mathrm{mmHg}$ (in patients $\geq 75$ years) appeared to be harmful, leading to higher cardiovascular/cerebrovascular morbidity and mortality than in patients with a SBP of 120-139 mmHg. ${ }^{38}$

Even though the J-curve phenomenon has been shown in many trials, its physiological correlation is not yet understood. As a result, this issue should be studied in a correctly designed trial comparable to the HOT (Hypertension Optimal Treatment) trial. ${ }^{39}$ The SPRINT (Systolic Blood Pressure Intervention Trial) trial $^{40}$ will hopefully clarify if a SBP of $<120 \mathrm{mmHg}$ will demonstrate lower cardiovascular disease event rates than a SBP of $140 \mathrm{mmHg}$. The trial will randomize approximately 9,250 patients $\geq 50$ years of age with a SBP of $\geq 130 \mathrm{mmHg}$ and with at least one additional cardiovascular disease risk factor, and will run until late 2018.

The ESH-CHL-SHOT (European Society of Hypertension and Chinese Hypotension League Stroke in Hypertension Optimal Treatment) trial will randomize 7,500 patients aged $\geq 65$ years with $\mathrm{SBP} \geq 140 \mathrm{mmHg}$ and history of previous stroke or transient ischemic attack (TIA). Patients will be randomly allocated into one of three different sitting SBP targets: $<145-135 \mathrm{mmHg},<135-125 \mathrm{mmHg}$, and <125 mmHg. The endpoint will be collected after approximately 4-5 years and will include recurrent stroke, major cardiovascular events, cognitive impairment, and dementia. ${ }^{41}$

\section{Ambulatory BP measurement: improved understanding of BP variability in the elderly}

$\mathrm{BP}$ variability in the elderly is high due to baroreflex failure and increased arterial stiffness, with periods of hyper- and hypotension throughout the day. White-coat hypertension, an increase in 24-hour pulse pressure and the prevalence of 24-hour isolated systolic hypertension, exaggerated ambulatory BP variability, morning BP surge, disrupted diurnal BP variation (non-dipping), and postural and postprandial hypotension are more common in the elderly and need to be considered so that treatment can be tailored appropriately. ${ }^{42}$ Twenty-four-hour SBP is more closely related to outcome (fatal or non-fatal cardiovascular events and/or total mortality) than office BP. Twenty-four-hour ambulatory pulse pressure demonstrates a greater association with stroke than with coronary artery disease (CAD). Outcome worsening will also be observed in non-dippers and in patients with nocturnal hypertension and with an exaggerated morning BP surge. Disruption of the circadian BP variation is also associated with orthostatic BP dysregulation. Postural and postprandial hypotension can be exaggerated by antihypertensive drugs (diuretics, alpha-blockers, neuroleptics, antidepressants) and is best diagnosed by ambulatory BP monitoring.

\section{Pharmacological treatment in the light of an aging organism}

Although oral absorption of drugs is not significantly affected by aging, drug distribution can be influenced by lean body mass and decreased proportion of body water. Drug halflife time and excretion can be disturbed by liver and kidney functional deterioration. Also, pharmacodynamic effects become relevant due to changes in end-organ responsiveness (decreased baroreceptor sensitivity leading to orthostatic hypotension) and may limit the use of vasodilators. A recent analysis of 61,661 elderly Japanese patients ${ }^{43}$ showed that the risk of adverse drug interactions in hypertensive patients increased with age and rose dramatically per 10,000 persondays from 2.0 (monotherapy) to 5.1 (co-medication), and up to 8.6 (polypharmacy). Further risk occurs with hyperglycemia induced by diuretics. BBs may cause acute cardiac decompensation in elderly patients with congestive heart failure, intermittent claudication in patients with peripheral vascular disease, and bronchoconstriction in patients with chronic obstructive pulmonary disease. Agents that increase 
the antihypertensive effect of BBs and calcium antagonists (CCBs), including cimetidine, antifungals, and grapefruit juice (cytochrome P4503A), should be considered with care. Non-steroidal anti-inflammatory drugs (NSAIDs), corticosteroids, erythropoietin, amphetamines, ergotamine, and anabolic steroids may further increase BP in elderly patients.

\section{Are there BP sex differences in the elderly?}

Both the prevalence and severity of hypertension are greater in elderly women than in elderly men. It is more difficult to achieve BP control in elderly women than in elderly men, and there seem to be differences in antihypertensive treatment patterns between them. Reasons for these differences are difficult to decipher, but could be due to inadequate treatment intensity, inappropriate drug choices, lack of compliance, treatment resistance because of biological factors, or to other factors (eg, central obesity, and so on).

\section{Is there a "right" drug for treatment of hypertension in the elderly?}

The question of the "right drug" in the very elderly has caused endless debate in various societies and guideline committees. One hundred and forty-seven randomized trials involving 464,000 patients have shown that all classes of BPlowering drugs have similar effects in reducing events and stroke for a given reduction in BP. ${ }^{44}$ Therefore, no drug has been consistently superior across all important outcomes. ${ }^{45}$ Only BBs (atenolol) and alpha-blockers (see alpha and beta-blocker section) should not be first-choice drugs as they are not superior to any other drug class for any outcome.

Another recent meta-analysis ${ }^{28}$ included 18 clinical studies and examined 55,569 hypertensive patients and 59,285 controls. The study compared all commonly used antihypertensive therapies with each other (baseline BP $157 / 86 \mathrm{mmHg}$; BP reduction to less than 140/80 $\mathrm{mmHg}$ ) and found that a similar BP reduction resulted in equivalent risk reduction for the substances compared.

A third prospective meta-analysis comparing younger and older hypertensives ( $\geq 65$ years) treated with different antihypertensive drugs substantiated previous results and found similar drug-class efficacy in younger and older patients. ${ }^{46}$ Hence, all these investigations show limited evidence of pivotal differences between various drug classes; treatment success is dependent on which collateral outcome is preferred.

\section{Guideline recommendations}

The latest ESH/ESC guidelines ${ }^{5}$ recommend antihypertensive treatment classes that appeared beneficial in reducing cardiovascular risk in randomized clincial trials. All hypertensive agents are recommended (Table 1), but diuretics and CCBs may be preferred in patients with isolated systolic hypertension (ISH). Former US guidelines (JNC7) favored thiazide-type-diruetics when commencing antihypertensive therapy in patients without other compelling indications. ${ }^{25}$ $\mathrm{JNC}^{14}$ lately backs away from the $\mathrm{JNC} 7$ recommendation that thiazide-type diuretics should be initial therapy in most patients, suggesting ACEIs, ARBs, CCBs, or thiazide-type diuretics are reasonable choices in nonblacks. In black patients, thiazide-type diuretics and $\mathrm{CCBs}$ are recommended as first-line therapy for hypertension. The ASH/ISH guidelines ${ }^{19}$ recommend different drugs for the initial therapy, depending on patients' age, race, and blood pressure levels. They mention ACEIs or ARBs for nonblack patients under the age of 60 and a CCB or thiazide in nonblack patients over the age of 60 . The most recent Canadian guideline update strongly emphasizes ISH as a special entity rather than simply acknowledging "age" alone, and recommends thiazides, ARBs, and CCBs. ${ }^{26}$ In contrast, NICE 2011 is fairly rigid with regard to treatment recommendations and does not recommend different treatment approaches for patients below and above 80 years of age. ${ }^{24}$

Since ACCOMPLISH (Avoiding Cardiovascular events through COMbination therapy in Patients Living with Systolic Hypertension), ${ }^{47}$ the ACEI/CCB combination has shown substantial benefits in the overall population and in patients $>70$ years. These results were reflected 2 years later in the 2011 NICE recommmendations. An overview of the most recent JNC7, ESH/ESC, CHEP and NICE guidelines is presented in Table 1. A comparison between the latest JNC8 and ASH/ISH is given in Table 2.

\section{Pharmacological treatment with different drug classes}

\section{Diuretics}

Thiazide diuretics (hydrochlorothiazide [HCTZ], chlorthalidone, and indapamide [thiazide-like]) are recommended for initiating therapy and are generally well tolerated. Diuretics control hypertension by inhibiting reabsorption of sodium and chloride ions from the tubules in the kidney. They lead to an early reduction of intravascular volume and peripheral vascular resistance, causing a reduction in BP. The thiazide-associated decrease in peripheral vascular resistance could be the result of a direct vasodilatory effect, 


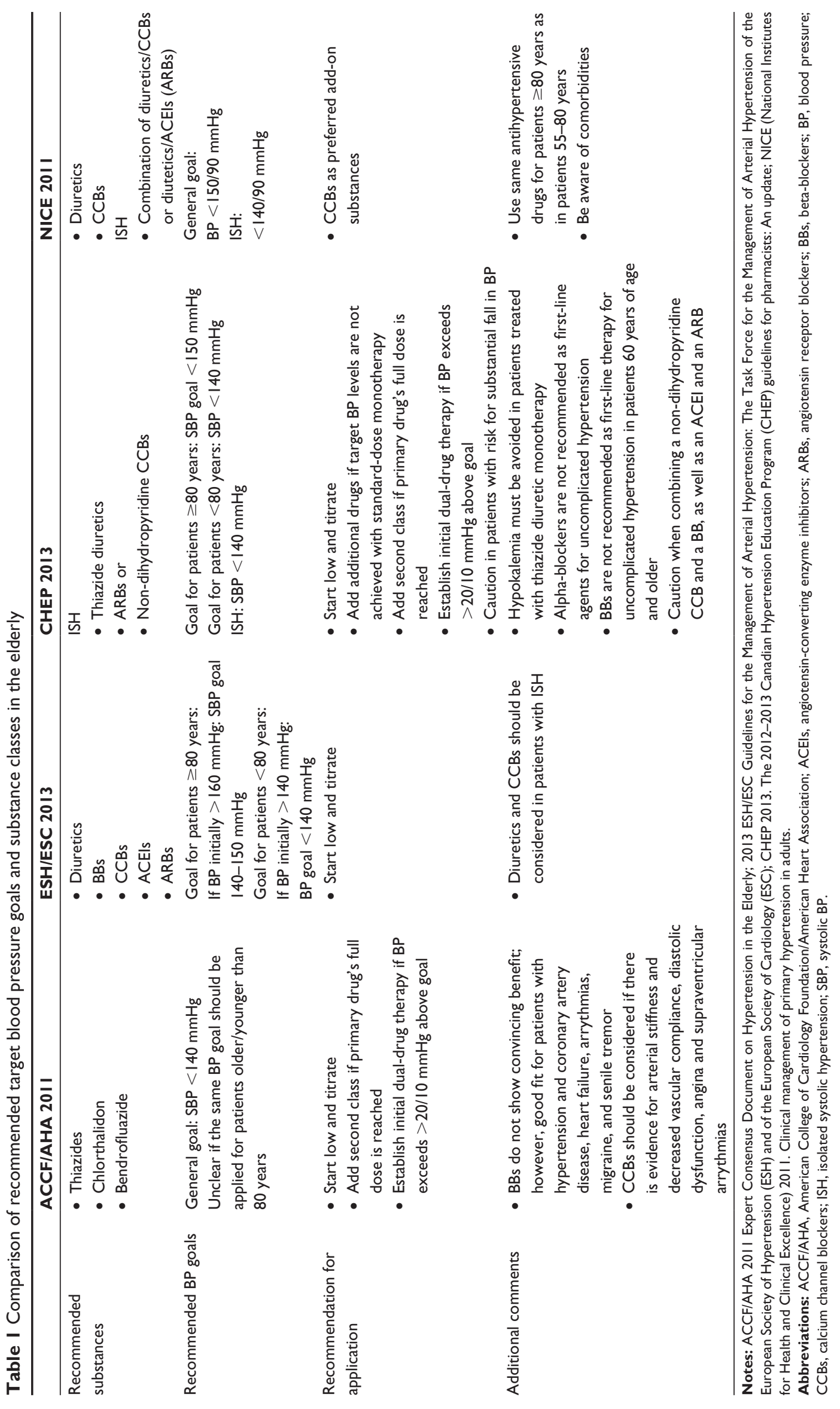


Table 2 Comparison of latest divergent guideline-recommendations of ASH/ISH 2013 and JNC8 2014

\begin{tabular}{|c|c|c|}
\hline & ASH/ISH 2013 & JNC8 2014 \\
\hline Recommended substances & $\begin{array}{l}\text { - Thiazides } \\
\text { - ARBs/ACEls } \\
\text { - CCBs }\end{array}$ & $\begin{array}{l}\text { - Thiazides } \\
\text { - ARBs/ACEls } \\
\text { - CCBs }\end{array}$ \\
\hline Recommended BP goals & $\begin{array}{l}\text { Goal for patients } \geq 80 \text { years: } \\
\text { - } \mathrm{SBP}<\mathrm{I} 40 / 90 \mathrm{mmHg} \text { for patients older than } \\
80 \text { years } \\
\text { - }<150 / 80 \mathrm{mmHg} \text { for some of the patients } \\
\text { that are even older } \\
\text { - If older patients ( }>80 \text { years) have chronic } \\
\text { kidney disease or diabetes melitus, BP should } \\
\text { be lowered below } 140 / 90 \mathrm{mmHg}\end{array}$ & $\begin{array}{l}\text { Goal for patients } \geq 60 \text { years: } \\
\text { - }<I 50 / 90 \mathrm{mmHg} \text {, } \\
\text { - no benefit to lower SBP }<140 \mathrm{mmHg} \\
\text { - If treatment is well tolerated and SBP is lowered }<140 \mathrm{mmHg} \text {, } \\
\text { no upwards adjustment is necessary }\end{array}$ \\
\hline $\begin{array}{l}\text { Recommendation for } \\
\text { application }\end{array}$ & $\begin{array}{l}\text { - First step: } C C B \text { s or thiazide diuretics as } \\
\text { first drug choice } \\
\text { - Second step: } A R B s, A C E I \text { (or CCB or thiazide } \\
\text { if } A C E I \text { or } A R B \text { used first) as second drug } \\
\text { - Third step: combination of CCB + ACEI or } \\
\text { ARB + thiazide diuretic }\end{array}$ & $\begin{array}{l}\text { - Initiate thiazide-type diuretic or } \mathrm{CCB} \text {, alone or in combination } \\
\text { in black patients } \\
\text { - Initiate thiazide-type diuretic or } \mathrm{ACEI} \text { or } \mathrm{ARB} \text { or } \mathrm{CCB} \text {, alone } \\
\text { or in combination in non-black patients }\end{array}$ \\
\hline Additional comments & $\begin{array}{l}\text { - Consideration of ethnicity and race } \\
\text { - Long-acting drugs should be preferred } \\
\text { - Availability (government and other agencies) } \\
\text { and affordability influences drug-choice }\end{array}$ & $\begin{array}{l}\text { Different possible drug-strategies including a) Maximizing first } \\
\text { medication before adding second, b) Add second medication } \\
\text { before reaching maximum dose of first medication } \\
\text { c) Start with two medication classes seperately or as fixed- } \\
\text { dose combination }\end{array}$ \\
\hline
\end{tabular}

Notes: ASH/ISH 2013 Clinical Practice Guidelines for the Management of Hypertension in the Community, A Statement by the American Society of Hypertension and the International Society of Hypertension, 2014 Evidence-Based Guideline for the Management of High Blood Pressure on Adults, Report From the Panel Members Appointed to the Eighth Joint National Committee (JNC8).

Abbreviations: CCBs, calcium channel blockers; ACEls, angiotensin-converting enzyme inhibitors; ARBs, angiotensin receptor blockers; BP, blood pressure; SBP, systolic blood pressure $\mathrm{ASH} / \mathrm{ISH}$, American Society of Hypertension and the International Society of Hypertension.

perhaps separately from the diuretic effect of HCTZ. One proposed effect of HCTZ is its direct vascular relaxant effects via opening of the calcium-activated potassium $(\mathrm{KCa})$ channel. Another hypothesis is that HCTZ inhibits carbonic anhydrase so that the $\mathrm{KCa}$ channel gets activated by the increased intracellular $\mathrm{pH}$. Further potential mechanisms of the direct and indirect vasodilatory effects of HCTZ are described by Duarte and Cooper-DeHoff. ${ }^{48} \mathrm{~A}$ number of clinical studies in the elderly have shown reduced incidence of cardiovascular events with thiazide (mean age ALLHAT [Antihypertensive and Lipid-Lowering treatment to prevent Heart Attack Trial]: 67 years, SHEP [the Systolic Hypertension in the Elderly Program]: 72 years, HYVET: 84 years, EWPHE [European Working Party on High blood pressure in the Elderly study]: 72 years).

However, at the same time, elderly patients run a higher risk of hypovolemia and are more prone to orthostatic hypotension due to reduced baroreceptor sensitivity.

Chlorthalidone differs pharmacokinetically from HCTZ due to its longer action. However, whether chlorthalidone really exhibits stronger potency has to be evaluated in future trials. In recent retrospective studies, no statistical difference in the primary outcome (composite of mortality and hospitalization for cardiovascular events) could be observed between chlorthalidone and HCTZ. On the contrary, chlorthalidone was associated with greater incidence of electrolyte abnormalities in older adults compared to HCTZ. ${ }^{49}$

Although thiazides had been considered first-line therapy in hypertension some controversy exists with regard to antihypertensive efficacy, effect on morbidity and mortality, and adverse drug reactions of this substance in the elderly. ${ }^{50}$

After a 1-year follow-up, only $39 \%$ of all patients remained on diuretic therapy. According to statistics on adverse drug reactions leading to hospitalization, diuretics are among the five leading drug classes. Finally, thiazide diuretics, as compared to thiazide-like diuretics (indapamide), increase uric acid, potentially expediting the development of gout through volume contraction and competition with uric acid for renal tubular secretion. All diuretics cause electrolyte disturbances; in conjunction with left ventricular hypertrophy this can provoke ventricular arrhythmias and sudden death. Thiazides are also diabetogenic, can cause dyslipidemia, and can reduce lithium excretion and precipitate lithium toxicity. In combination with $\mathrm{BBs}$, thiazides have the potential to increase fatigue and glucose levels. While NSAIDs hamper the potency of thiazides, potassium and renal function need to be monitored carefully in light of renal insufficiency and the danger of hyperkalemia. 


\section{Beta-blockers}

BBs should be used in combination therapy, usually with diuretics in elderly patients who have additional cardiovascular conditions, such as coronary heart disease (CHD), particularly in individuals with a history of myocardial infarction (MI), systolic heart failure, or arrhythmias. The inhibition of catecholamine-mediated cardiotoxic effects and hyperactivity of the sympathetic system play a role in younger patients, whereas the mechanism for lowering BP is based on a decrease of cardiac output, inhibition of renin release, decrease of angiotensin II (AII) production, and blockade of presynaptic adrenoceptors that decrease central vasomotor activity. ${ }^{51}$ In several large studies and meta-analyses, BBs have failed to provide benefits as a firstline antihypertensive drug compared to other therapies..$^{52,53}$ BBs only show modest reductions in cardiovascular events and no significant effects on mortality. ${ }^{51,54}$ Reasons for the negligible cardiovascular protection include their inability to lower central aortic pressure (pseudo-antihypertensive efficacy), unfavorable metabolic effects, and their lack of regressive effects on left ventricular hypertrophy and endothelial dysfunction.

In ISH patients, BBs lead to a compensatory increase in stroke volume due to their negative chronotropic effect. Subsequently, this leads to a further elevation in SBP and a decrease in DBP, which exacerbates pulse pressure even more. Although it was thought that lowering heart rate is associated with a positive effect on outcome, this assumption has not held true. ${ }^{55}$

There can also be differences between various sub-types of BBs. The newer BBs, such as nebivolol and carvedilol, which have vasodilatory properties, may provide better morbidity and mortality outcomes and safety profile. A definitive answer would have to come from prospective randomized controlled trials. Overall, BB tolerability is poor, indicated by substantial drop-out rates in clinical trials. Drowsiness, lethargy, sleep disturbance, visual hallucinations, and depression are side-effects that hamper life quality, even more so in elderly and very elderly patients.

\section{Calcium channel blockers}

Three sub-classes of CCBs block the influx of calcium ions into the cells of vascular smooth-muscle and myocardial tissue: phenylalkylamines (verapamil), benzothiazepines (diltiazem), and dihydropyridines (eg, nifedipine, amlodipine, and nitrendipine). CCBs inhibit the contraction of coronary and peripheral arterial smooth-muscle cells that are considerably more dependent on external calcium than the heart and skeletal muscle. As a result, $\mathrm{CCBs}$ dilate coronary and peripheral arteries without jeopardizing the heart or muscle contractibility. In addition, they influence the sinus node function, atrioventricular conduction, and coronary circulation. A special attribute of dihydropyridines is the decrease of cytosolic free calcium, leading to a lower vasomotor tone (especially at the arteriolar level), and thus lower peripheral resistance. With this mode of action, CCBs are particularly suited for the treatment of stiffening arteries, angina, and supraventricular arrhythmias. Side-effects of dihydropyridines are ankle edema, headache, and postural hypotension. Verapamil and diltiazem may cause heart block in elderly patients. The first generation of CCBs (nifedipine, verapamil, and diltiazem) should be avoided in patients with left ventricular systolic dysfunction. A variety of studies have shown dihydropyridines to be beneficial in patients with ISH, high age, diabetes, atherosclerosis, stroke, ${ }^{56}$ and dementia. ${ }^{57}$ One meta-analysis involving 9,138 patients $^{58}$ demonstrated $^{2}$ that CCBs attenuate the rate of progression of carotid intima-media thickening. Further benefits in favor of dihydropyridines have been reported in the CAFÉ (Conduit Artery Function Evaluation) study ${ }^{59}$ where the combination of CCB/ACEI yielded a higher central BP-lowering effect than the ACEI/diuretic combination. Interestingly, no difference has been reported for brachial BP. The CAFÉ study provides a plausible explanation, at least in part, for the better clinical outcome in patients treated with amlodipine/ perindopril. The ACCOMPLISH trial has substantiated these findings. Benazepril/amlodipine was shown to be superior, with a $20 \%$ lower incidence of cardiovascular mortality and a $17 \%$ lower rate of cardiovascular events than HCTZ/ benazepril, independent of age and the presence of CAD. ${ }^{60}$ On the other hand, a recent meta-analysis of 31 randomized controlled trials involving 273,543 participants showed that CCBs were not different to ACEIs and diuretics ${ }^{61}$ for lowering stroke rates. In analogy to the ACCOMPLISH trial, ${ }^{60}$ the COLM (Combination of OLMesartan and CCB or Low Dose Diuretics in High Risk Elderly Hypertensive Patients) study compares combination therapy using an ARB (olmesartan) and a CCB with the combination of an ARB and a diuretic in high-risk elderly (65-84 years) hypertensive patients. ${ }^{62} \mathrm{~A}$ total of more than 4,000 patients were recruited and were followed up for at least 3 years. The study has been completed, but the results are still outstanding. ${ }^{62} \mathrm{In}$ the NICE guidelines, ${ }^{24} \mathrm{CCBs}$ are recommended as initial therapy for all patients older than 55 years of age. This recommendation is based on the low withdrawal rates with CCBs found in the ASCOT (Anglo-Scandinavian Cardiac 
Outcome Trial), ${ }^{63}$ as well as the low association between $\mathrm{CCB}$ medication and fewer revascularization procedures leading to a combined medico-economic rationale. Also, the JNC7, JNC8, ASH/ISH (>60 years of age), and ESH/ ESC guidelines have CCBs included in their initial drug therapy (Tables 1 and 2).

\section{Drugs that influence the renin angiotensin aldosterone system}

Angiotensin-converting enzyme inhibitors

ACEIs block the conversion from angiotensin I to the vasoconstrictor AII, leading to a systematic decrease in blood-vessel tension and blood volume, without affecting heart rate via reflex stimulation. AII damages the endothelium by increasing oxidative stress while reducing nitric oxide bioavailability that provokes vascular remodeling, atherosclerosis, and arterial stiffening. Multiple clinical trials (ALLHAT, ${ }^{86}$ STOP-2 [The Second Swedish Trial in Old Patients with Hypertension-2], ${ }^{64}$ and HOPE [The Heart Outcomes Prevention Evaluation Study] ${ }^{65}$ ) found that ACEIs lowered BP equally effectively compared to other drugs ${ }^{66}$ and demonstrated lower morbidity and mortality in the elderly. ${ }^{53}$ ACEIs seem to be most effective in patients with comorbidities, such as left ventricular hypertrophy, congestive heart failure and diabetes, to reduce cardiovascular death, stroke, and myocardial infarction, ${ }^{67}$ although ACEIs appear to be inferior to CCBs with regard to stroke risk reduction; ${ }^{68}$ centrally acting ACEIs that cross the blood-brain barrier may do so by inhibiting the brain's ACE-driven degradation of amyloid-beta protein. In elderly diabetic patients, the use of ACEIs to preclude and slow the progression of renal disease and to prevent kidney failure still has to be proven in large-scale clinical trials. In a sub-study of $\mathrm{HOPE}^{69}$ involving diabetic patients (mean age 65 years), the primary endpoints (myocardial infarction, stroke, and cardiovascular death) and secondary endpoints (total mortality, heart failure, and TIA) were significantly lowered. Elsewise, evidence can only be extrapolated from middle-aged patients who have been treated with ARBs. ${ }^{70}$ Notwithstanding the results of a recent meta-analysis ${ }^{71}$ in elderly patients, the benefits of an ACEI or an ARB therapy (see the next section) should not be denied, but continuous monitoring of renal function and electrolytes (especially potassium) and avoidance of NSAIDs and potassium in the diet (eg, potassium-sparing diuretics, potassium supplements, and potassium-rich food) are recommended and will help to diminish the risks associated with this therapy.

\section{Angiotensin-receptor blockers}

ARBs block the activation of AII AT1 (Angiotensin-IIReceptor-Subtype-1) receptors. As ARBs trigger fewer side-effects, they are alternatives when adverse events of ACEIs are not tolerable. This applies specifically to ACEIinduced coughing. Improved or similar outcome with ARBs compared with other drugs has been demonstrated in several trials (LIFE [Losartan Intervention for Endpoint Reduction], VALUE [Valsartan Antihypertensive LongTerm-Use Evaluation]). ${ }^{72,73}$ ARBs are effective in reducing microalbuminuria levels and end-stage renal disease rates in patients with diabetic nephropathy. However, optimal BP thresholds and targets in elderly chronic kidney disease (CKD) patients still remain to be determined. ${ }^{71}$ ARBs exhibit beneficial effects in elderly patients with stroke and heart failure (SCOPE [Study on COgnition and Prognosis in the Elderly], MOSES [Morbidity and Mortality after Stroke, Eprosartan Compared with Nitrendipine for Secondary Prevention], ACCESS [Acute Candesartan Cilexetil Therapy in Stroke Survivors], ValHeft [Valsartan Heart Failure Trial], and CHARM [Candesartan in Heart Failure: Assessment of Reduction in Mortality and Morbidity]). ${ }^{74-78}$ In CKD and heart-failure patients, the combination of ACEIs and ARBs should be avoided. Evidence has been provided that there is an increased risk of renal dysfunction and hyperkalemia, with limited additive efficacy. ${ }^{79}$ In a recent meta-analysis, all-cause mortality reduction in hypertensive patients was driven primarily by ACEIs compared to ARBs. ${ }^{80}$ Relevant side effects are displayed in Table 3.

ACEIs or ARBs are recommended only in patients younger than 55 years in the NICE guidelines. ${ }^{24} \mathrm{All}$ other guidelines (JNC7, JNC8 ESH/ESC, CHEP) do recommend $\mathrm{ACEI}$ and $\mathrm{ARBs}$ as first line therapy for nonblack patients.

\section{Direct renin inhibitors}

Aliskiren appears to be as effective as ARBs and ACEIs in lowering BP in the elderly. ${ }^{81}$ In the AGELESS (aliskiren for geriatric lowering of systolic hypertension: a randomized controlled trial) trial, ${ }^{82}$ the drug was found to be more effective and better tolerated than ramipril in patients with ISH. The major side-effect is mild diarrhea, which usually does not lead to discontinuation. In patients with type II diabetes or in patients with glomerular filtration rate (GFR) below $60 \mathrm{~mL} / \mathrm{minute} / 1.73 \mathrm{~m}^{2}$, the US Food and Drug Administration (FDA) and the European Medicines Agency (EMA) do not recommend the combined use of aliskiren and blockers of the renin angiotensin aldosterone system (RAAS). This 
Table 3 Most common drug-related side-effects of the main substance classes

\begin{tabular}{|c|c|}
\hline Drug class & Adverse effects \\
\hline Thiazide and loop diuretics & $\begin{array}{l}\text { - Hypokalemia, hyponatremia, hypomagnesemia } \\
\text { - Volume-depletion and orthostatic hypotension } \\
\text { - Renal impairment, hyperuricemia, gout, lipid alterations, hyperglycemia, insulin resistance } \\
\text { - NSAIDs reduce thiazide potency } \\
\text { - Erectile dysfunction and possibly impotence } \\
\text { - Reduction of lithium excretion and precipitate lithium toxicity } \\
\text { - Potential to increase fatigue and lethargy } \\
\text { - Pro-diabetogenic potential in combination with BBs } \\
\text { - Increase of urinary frequency, leg cramps } \\
\text { - Decrease of renal blood flow, creatinine clearance, GFR }\end{array}$ \\
\hline Potassium-sparing diuretics & - Hyperkalemia, hypotension \\
\hline BBs & $\begin{array}{l}\text { - Sinus bradycardia, fatigue, AV-nodal heart block bronchospasm, aggravation of acute heart failure } \\
\text { - Intermittent claudication, confusion, hyperglycemia } \\
\text { - Diabetes mellitus } \\
\text { - Drowsiness, lethargy, sleep disturbance, visual hallucinations, depression, blurring of vision, } \\
\text { nightmares } \\
\text { - Pulmonary side-effects (increased airway resistance in asthmatics) } \\
\text { - Peripheral vascular side-effects (cold extremities, Raynaud's phenomenon) } \\
\text { - Erectile dysfunction }\end{array}$ \\
\hline ACEls & $\begin{array}{l}\text { - Cough, hyperkalemia } \\
\text { - Angioneurotic edema } \\
\text { - Rash, altered taste sensation, renal impairment }\end{array}$ \\
\hline ARBs & - Hyperkalemia, renal impairment \\
\hline CCBs (non-dihydropyridines) & $\begin{array}{l}\text { - Rash, sinus bradycardia, heart block, heart failure, constipation (verapamil), gingival hyperplasia } \\
\text { - Ankle edema, headache and postural hypotension }\end{array}$ \\
\hline CCBs (dihydropyridines) & $\begin{array}{l}\text { - Peripheral edema, heart failure, tachycardia } \\
\text { - Aggravation of angina pectoris (short-acting agents) }\end{array}$ \\
\hline Direct vasodilators & $\begin{array}{l}\text { - Tachycardia, fluid retention } \\
\text { - Angina pectoris }\end{array}$ \\
\hline Alphal-adrenergic antagonists & - Hypotension \\
\hline $\begin{array}{l}\text { Alpha-beta adrenergic blockers } \\
\text { (vasodilator-beta adrenergic blockers) }\end{array}$ & - Hypotension, heart block, sinus bradycardia, bronchospasm \\
\hline Central-acting substances & - Sedation, constipation, dry mouth \\
\hline Direct renin inhibitors & - Mild diarrhea \\
\hline
\end{tabular}

Abbreviations: ACEls, angiotensin-converting enzyme inhibitors; ARBs, angiotensin receptor blockers; BBs, beta-blockers; CCBs, calcium channel blockers; NSAIDs, nonsteroidal anti-inflammatory drugs; GFR, glomerular filtration rate; eGFR, estimated glomerular filtration rate; AV, atrioventricular.

decision is based on results from the interrupted ALTITUDE (Aliskiren Trial In Type 2 Diabetes Using Cardio-Renal Endpoints) trial, ${ }^{83}$ in which the incidence of primary endpoints (cardiovascular and renal events) was not improved, but more adverse events were observed in the combination arm (hyperkalemia). In the ASTRONAUT (The Aliskiren Trial on Acute Heart Failure Outcomes) trial, ${ }^{83}$ the combination of aliskiren and an ARB also did not show an improvement in post-discharge mortality and heart failure readmissions, although significant decreases in N-terminal pro-brain natriuretic peptide (NT-proBNP) were observed. Patients on aliskiren on top of standard therapy displayed a significantly higher rate of hyperkalemia, worsening renal function, and hypotension. The final results of the ATMOSPHERE (the Aliskiren Trial of Minimizing OutcomeS for Patients with HEart failure) study ${ }^{84}$ (patients with chronic heart failure treated with the combination of aliskiren and enalapril) still need to be reported before final conclusions can be drawn, especially for the elderly population. ${ }^{85} \mathrm{JNC}^{19}$ guidelines do not recommend direct renin inhibitors as there have been no studies demonstrating their benefits on kidney or cardiovascular outcomes.

\section{Other agents}

Adrenergic blockers (eg, doxazosin) and centrally acting antihypertensive drugs (eg, clonidine, methyldopa, and reserpine) are not recommended for the treatment of hypertension in the elderly as their efficacy/adverse-effect profile is not beneficial. ${ }^{53}$

Alpha-adrenergic blockers dilate the arterial wall by blocking the vasoconstrictive effects of alpha-adrenergic receptors. Although alpha-blockers are very effective in 
Table 4 Comparison of recommended substance classes in special situations in hypertension management

\begin{tabular}{|c|c|c|}
\hline Cond & $\begin{array}{l}\text { Recommended } \\
\text { drug } \\
\text { ESH/ESC } 2013\end{array}$ & $\begin{array}{l}\text { Recommended } \\
\text { drug } \\
\text { ACCF/AHA 20I I }\end{array}$ \\
\hline $\begin{array}{l}\text { Asymptomatic } \\
\text { atherosclerosis/ } \\
\text { coronary artery } \\
\text { disease risk }\end{array}$ & CCBs, ACEls & $\begin{array}{l}\text { Diuretics, BBs, } \\
\text { ACEls, CCBs, } \\
\text { mineralocorticoid } \\
\text { receptor antagonists }\end{array}$ \\
\hline $\begin{array}{l}\text { Recurrent stroke } \\
\text { protection }\end{array}$ & Any drug reducing $\mathrm{BP}$ & Diuretics, ACEls \\
\hline $\begin{array}{l}\text { Recurrent AMI } \\
\text { protection }\end{array}$ & BBs, ACEls, ARBs & $\begin{array}{l}\text { BBs, ACEls, } \\
\text { mineralocorticoid } \\
\text { receptor antagonists }\end{array}$ \\
\hline $\begin{array}{l}\text { End stage renal disease/ } \\
\text { proteinuria/chronic } \\
\text { kidney disease }\end{array}$ & ACEls, ARBs & ACEls, ARBs \\
\hline Diabetes mellitus & ACEls, ARBs & $\begin{array}{l}\text { Diuretics, BBs, } \\
\text { ACEls, ARBs, CCBs, } \\
\text { mineralocorticoid } \\
\text { receptor antagonists }\end{array}$ \\
\hline Heart failure & $\begin{array}{l}\text { Diuretics, BBs, ACEls, } \\
\text { ARBs, mineralocorticoid } \\
\text { receptor antagonists }\end{array}$ & - \\
\hline Black patients & Diuretics, CCBs & - \\
\hline \multicolumn{3}{|c|}{$\begin{array}{l}\text { Other factors not mentioned in guideline recommendations applicable } \\
\text { to the elderly/very elderly }\end{array}$} \\
\hline Adherence & CCBs, ARBs & \\
\hline Costs savings & Diuretics, BBs, costs/ad & rence: ARBs \\
\hline Dementia & ACEls, CCBs & \\
\hline
\end{tabular}

Notes: ACCF/AHA 20II Expert Consensus Document on Hypertension in the Elderly: A Report of the American College of Cardiology Foundation Task Force on Clinical Expert Consensus Documents developed in collaboration with the American Academy of Neurology, American Geriatrics Society, American Society for Preventive Cardiology, American Society of Hypertension, American Society of Nephrology, Association of Black Cardiologists, and European Society of Hypertension; 2013 ESH ESC Guidelines for the Management of Arterial Hypertension: The Task Force for the Management of Arterial Hypertension of the European Society of Hypertension $(E S H)$ and of the European Society of Cardiology (ESC).

Abbreviations: ACCF/AHA, American College of Cardiology Foundation/ American Heart Association; ACEl, angiotensin-converting enzyme inhibitors; AMI, acute myocardial infarction; ARBs, angiotensin receptor blockers; BBs, beta-blockers; $\mathrm{CCBs}$, calcium channel blockers.

lowering BP, they often cause adverse events, such as postural hypotension, especially in patients receiving other vasodilators or diuretics. Since in the ALLHAT study ${ }^{86}$ the doxazosin arm demonstrated a $25 \%$ increase in cardiovascular endpoints and tripled the risk of congestive heart failure compared to chlorthalidone, alpha-blockers are no longer used in treatment combinations or just as third- or fourth-line agents, for example in isolated hypertension.

\section{Summary of treatment per disease condition}

The recent ESH/ESC guidelines suggest a condition-drug correlation. ${ }^{87}$ As there is no evidence that different drugs should be used according to age and sex, the guideline allocations may also be applied to elderly patients (Table 4).

\section{The comorbidity of dementia}

Elderly patients have an increased risk of hypertensioninduced dementia and cognitive dysfunction. High BP is also a predictor of stroke and vascular brain lesions. ${ }^{88}$

Vascular dementia is a consequence of cognitive impairment caused by hypertensive angiopathy. ${ }^{89}$ The underlying mechanism seems to be the elongation and tortation of blood vessels leading to an increase in $\mathrm{BP}$ in order to maintain blood flow; blood vessel wall thickness, and subsequent rigidity increase. ${ }^{90}$ Subcortical white matter is damaged through blood flow impairment, hypoperfusions, and micro-ruptures of cerebral blood vessels. ${ }^{91}$

However, to date there is no hard evidence regarding whether or not antihypertensive therapy has an impact on cognitive decline and dementia and if white-matter lesions can be prevented with antihypertensive therapy. This ambiguity is caused by several studies that revealed a curvilinear relationship between BP and cognitive function, in that low BP in late life is associated with a higher incidence of dementia. ${ }^{92}$ Another finding comes from a recent French cohort study, which showed that BP variability and not mean BP was associated with an increased risk of incident dementia. ${ }^{93}$ The MIND sub-study of the SPRINT trial (SPRINT Memory and cognition IN Decreased hypertension: SPRINT-MIND) may provide more insights on cognitive function by assessing the Mini Mental State results of elderly people with SBPs of 100 $\mathrm{mmHg}, 120 \mathrm{mmHg}$, and $180 \mathrm{mmHg} .{ }^{94}$

Thus, to date it remains unclear whether benefits in the prevention of cognitive impairment are derived from lowering BP or from the choice of a particular drug class. The comprehensive PROGRESS (Perindopril Protection Against Recurrent Stroke Study) sub-study ${ }^{95}$ will hopefully address this issue by assessing the protective effects of perindopril and indapamide. Even though the underlying mechanisms are unknown, it is assumed that blockage of the cerebral ACE system and facilitating cholinergic activation can prevent cognitive decline. ${ }^{96} \mathrm{Also}$, telmisartan is assumed to interplay with the hippocampal brain-derived neurotrophic factor/ tropomyosin-related kinase B. ${ }^{97}$ In the smaller Honululu-Asia Aging study, BBs seemed to be associated with a lower risk of developing cognitive impairment, ${ }^{98}$ and a recent Spanish review $^{99}$ highlights the advantages of CCBs. Nitrendipine and lercanidipin in particular seem to have specific neuroprotective effects. The latter is responsible for substantial and longacting vasodilation, and may therefore be indicated to reduce vascular dementia. In light of conflicting evidence, CCBs and ACEIs may be recommended for preventive use in elderly and very elderly patients with dementia (Table 1 ). 


\section{Changes in hypertension treatment through the aging process}

Primarily, reduction of BP is more important than the agent used to reach that goal. Thus, the four basic drug classes, namely ACEIs, ARBs, CCBs, and diuretics, are all suitable as first-line therapy to treat arterial hypertension in both elderly ( $\geq 65$ years) and very elderly patients ( $\geq 80$ years). BBs should be administered cautiously, with the exception of prior myocardial infarction, heart failure, and arrhythmia. The choice of antihypertensive agent should be individually adjusted according to the tolerability of the corresponding drugs and underlying comorbidities. A successful antihypertensive treatment without side-effects should be principally maintained when patients become older, but modified according to the stage of aging in order to maintain the SBP goals of $<140$ $\mathrm{mmHg}$ in patients $<80$ years and $140-150 \mathrm{mmHg}$ in patients $\geq 80$ years, as recommended in the current $\mathrm{ESH} / \mathrm{ESC}$ guidelines. ${ }^{5}$ In a recent review on SBP targets for the elderly by Denker and Cohen ${ }^{100}$ and as elucidated by Paul James: '[...] if you gotten someone's [systolic] BP to 140 or $135 \mathrm{mmHg}$ on medicine and they are doing well then you need to take them off medicine and get their BP closer to $150 \mathrm{mmHg} .{ }^{15}$ Data suggest that the activity of the RAAS system, including plasma renin activity, is remarkably lower in the elderly.101 Thus, drugs targeting the RAAS might become less effective and patients should be monitored more intensively.

\section{Medical rationale for single-pill combinations in the elderly}

Only $20 \%$ of patients $\geq 65$ years show good adherence to medication. ${ }^{102}$ As a result, treatment success is often impaired. Overall, utilization of multiple antihypertensive drugs in the elderly has been observed, with $38 \%$ of patients receiving three or more antihypertensive drugs. ${ }^{103} \mathrm{~A}$ study found that non-vascular comorbidities are also negatively correlated with antihypertensive drug use in the elderly. ${ }^{104}$ Approximately $50 \%$ of patients discontinue their treatment within only 1-year, ${ }^{105}$ and a high percentage of drug-related admissions to hospitals are caused by non-adherence to medication.

An older but nicely designed systematic review on the association between dose and medication compliance indicated that compliance dropped from $79 \% \pm 14 \%$ with one daily drug to $51 \% \pm 20 \%$ with four daily drugs. ${ }^{107}$ Decreasing the number of tablets can therefore improve adherence to treatment. ${ }^{108}$ In addition, prescription of single-pill combinations (SPCs) appears to be useful in reducing side-effects and bringing more patients to goal. ${ }^{109}$ Combined therapies can increase responder rates up to $70 \%{ }^{110}$ and reduce sideeffects by neutralizing counter-regulatory mechanisms. In a survey conducted in Thuringia, $85.1 \%$ of physicians treated their hypertensive patients early on with combination therapy. ${ }^{111}$ ESH/ESC guidelines ${ }^{5}$ recommend to start combination therapy with marked BP elevation and/or high/very high CV risk. JNC8 guidelines ${ }^{14}$ leave it to the physicians' diligence, which of the 3 strategies described to adopt, and tailor the therapy according to the individual circumstances, clinician and patient preferences, and drug tolerability (Table 2).

\section{A focus on compliance: looking beyond mode of application}

Compliance problems are not caused exclusively by mode of application. The composition of prescribed drugs and patient sex also influence compliance behavior. Highest adherence has been found in patients taking CCBs and ARBs, while BBs and diuretics have been associated with low adherence. ${ }^{112}$ A cohort study of 2,194 patients identified the most prominent factors of low adherence in the elderly to be high body mass index in men, dissatisfaction with communication of the health care provider, and depression in women. ${ }^{113}$ Furthermore, consultation of multiple doctors has been shown to be associated with a lower likelihood of achieving target BP in patients aged $>80$ years. ${ }^{114}$ A Swiss study indicated that older physicians in rural areas showed more hesitation concerning the use of SPCs in elderly patients. ${ }^{10} \mathrm{It}$ is likely that SPCs are perceived as impractical when medication adjustments need to be performed frequently. In addition, it must be mentioned that cortical dementia, for example, also increases the risk of non-adherence to medication. Thus, physicians may believe that in a twice-daily scheme the probability of taking at least one dosage/day is higher than with a SPC where the forgiveness factor is low. Based on the fact that approximately $18 \%$ of octogenarians show an impairment of cortical function or dementia, the prescription of SPCs must be evaluated carefully. Furthermore, it must not be forgotten that the initial use of a SPC can result in a substantial drop in BP.

\section{Early detection of cardiovascular disease}

Hypertension in the elderly is a very common biomarker to detect developing cardiovascular disease early and reliably. Changes in hypertension levels reflect subtle perturbations and provide the opportunity for prevention or regression at an early and potentially modifiable disease stage. Heart 
failure, arrhythmias, valvular heart disease, and CHD are highly prevalent among octogenarians. Because treatment variation is more restricted in the elderly due to limitations pertaining to homeostatic and adaptive capacity, aggravation of existing diseases should be prevented. The currently applied methodologies (eg, electrocardiography and echocardiography) do not have high detection sensitivity and cannot always be used in routine assessment (ie, they are costly and time-consuming). For example, the diagnosis of left ventricular hypertrophy (LVH) has been demonstrated to be predictive of major cardiovascular events, including stroke and all-cause mortality, independent of BP. Conversely, patients who achieve LVH regression during follow-up are much less likely to experience morbid events than those with persistence of LVH. ${ }^{115}$ Also, NT-pro-BNP/BNP and cardiac troponins are related to structural and functional abnormalities that may progress to symptomatic heart disease, eg, LVH and LV systolic and diastolic dysfunction. ${ }^{116}$ Results from high-sensitivity cardiac troponin (hs-cTn) assays were also strongly related to cardiac abnormalities, namely LV systolic dysfunction and increased LV mass and LV dimensions portending mortality and heart failure hospitalization. Shown in three different large population-based cohort studies strong and graded associations were seen linking hypertension, diabetes, and CKD with higher cTn levels. ${ }^{116}$ Combining information derived from NT-pro-BNP/BNP and/or cTn may provide complementary utility to risk-stratify subjects to different categories beyond traditional risk factors. ${ }^{117}$ Combined with clinical information (eg, LVH), biomarker testing may allow identification of patients with a malignant subphenotype of LVH with a high risk for progression to heart failure and $\mathrm{CV}$ death ${ }^{118}$ or may in combination with electrocardiography lead to a similar sensitivity as echocardiography with a tenth of the costs. ${ }^{119}$ However, to date, studies have shown considerable heterogeneity due to different thresholds (cut-offs) used and varying prevalence of the abnormalities screened and concomitant cardiovascular diagnoses. Furthermore, the biomarker results may be confounded by several non-cardiac conditions, such as age, sex, renal function, and metabolic status. Results suggest that risk (heart failure, CVD death) associated with higher cTn levels can be dynamic. If therapies or lifestyle factors can be identified that can prevent further troponin increase, or, better yet, reduce troponin levels assessed in serial measurement, then heart failure risk may also be modifiable. There are currently no studies evaluating the effectiveness of a biomarker based treatment intervention on hard outcomes in either a general or an old population with subclinical but potentially modifiable cardiorenal organ damage stages.

\section{Economic aspects of antihypertensive treatment in the elderly}

Antihypertensive treatment has a huge economic impact on health systems. In general, two factors impact on treatment costs: 1) duration of treatment, and 2) mode of application. Data have shown that patients treated for longer than 10 years are more cost-intensive. ${ }^{117}$ This may be due to resistance to change to alternative and cheaper combinations once treatment is successful. In Switzerland, fewer SPCs are prescribed in the very elderly than in younger patients, ${ }^{10}$ which impacts therapy costs. Thus, daily therapy costs were found to be higher in patients aged 65-79 and $>80$ years than in patients aged $<65$ years.

In many markets, treatment costs are higher for ARBs than for ACEIs. However, it must be noted that despite nominally higher daily treatment costs, the antihypertensive effect and adverse side-effect profile for ARBs are more favorable than for older drugs, such as diuretics or BBs. Increased compliance with ARBs resulting in substantial cost savings ${ }^{118}$ may therefore justify higher daily treatment costs. Despite the findings of an Italian investigation reporting diuretics and BBs to be highly cost-effective, blood pressure control rates remained low with these drugs. ${ }^{119}$ Data from another Swiss survey indicated an exceedingly high use of diuretics in primary care ${ }^{120}$ as diuretics are often perceived to be the preferred approach for initial treatment of mild to moderate hypertension. ${ }^{121}$ Considering the increased costs for potential new-onset diabetes of USD \$549 per patient, the use of diuretics/BBs has been shown to be economically and medically unpropitious. ${ }^{122}$ This finding can be backed with data from an analysis showing substantial savings in Great Britain and Sweden with respect to new-onset diabetes by using CCBs instead of BBs. ${ }^{122}$

\section{Conclusion}

The increasing number of elderly ( $\geq 65$ and $<80$ years) and very elderly ( $\geq 80$ years) patients, plus restricted evidence from randomized controlled trials consolidated in different guidelines, means that antihypertensive treatment remains challenging in this patient population. It is therefore the physician's responsibility to individualize treatment, taking important aspects such as the J-curve effect, age, comorbidities, and co-medication into consideration. The central questions remain: whom to treat with which drug class, when to initiate treatment, and what should be optimal goals in this population. Furthermore, other modifiable cardiovascular risk factors, such as diabetes mellitus and chronic kidney disease, 
also need to be integrated into the treatment strategy. The principle to start low and go slow will probably help primarily in patients with orthostatic hypotensive problems and kidney insufficiency. BP measurement should also be conducted in a standing position, and 24-hour ambulatory BP measurements are recommended. The newly started studies, SPRINT and ESH-CHL-SHOT, should help us to define optimum BP values for elderly patients more accurately. Future studies should also include 24-hour ambulatory BP measurement to gain more insight into an optimal treatment algorithm for the individual characteristics of a BP profile. Care should also be improved by accelerating adoption and implementation of standardized treatment approaches nationwide. ${ }^{21,23}$ Novel non-pharmacological interventions, namely renal sympathetic denervation and carotid baroreceptor stimulation, should also be assessed to provide further armamentarium in managing the ever-increasing number of hypertensive elderly patients.

\section{Disclosure}

Kaiser E and Schäfer H work for Roche Diagnostics and are former employees of Novartis Pharma Germany/Switzerland. The authors report no other conflicts of interest in this work.

\section{References}

1. Simpson FO. Long-term cost and life-expectancy consequences of hypertension. J Hypertens. 1998;16(8):1099-1100.

2. Pimenta E, Oparil S. Management of hypertension in the elderly. Nat Rev Cardiol. 2012;9(5):286-296.

3. Statistisches Bundesamt. Bevölkerung Deutschlands bis 2060. 12. koordinierte Bevölkerungsvorausberechnung [German population up to 2060. 12. Coordinated population projection]. 2009. Available from https://www. destatis.de/DE/Publikationen/Thematisch/Bevoelkerung/VorausberechnungBevoelkerung/BevoelkerungDeutschland2060Presse51242040990 04.pdf?_blob=publicationFile. Accessed February 20, 2014.

4. Aronow WS, Fleg JL, Pepine CJ, et al. ACCF/AHA 2011 expert consensus document on hypertension in the elderly: a report of the American College of Cardiology Foundation Task Force on Clinical Expert Consensus Documents developed in collaboration with the American Academy of Neurology, American Geriatrics Society, American Society for Preventive Cardiology, American Society of Hypertension, American Society of Nephrology, Association of Black Cardiologists, and European Society of Hypertension. J Am Soc Hypertens. 2011;5(4):259-352.

5. Mancia G, Fagard R, Narkiewicz K, et al. Task Force Members. 2013 ESH/ESC Guidelines for the management of arterial hypertension: the Task Force for the management of arterial hypertension of the European Society of Hypertension (ESH) and of the European Society of Cardiology (ESC). J Hypertens. 2013;31(7):1281-1357.

6. Gueyffier F, Bulpitt C, Boissel JP, et al. Antihypertensive drugs in very old people: a subgroup meta-analysis of randomised controlled trials. INDANA Group. Lancet. 1999;353(9155):793-796.

7. Peters R, Beckett N, Poulter R, et al. Kidney function in the very elderly with hypertension: data from the hypertension in the very elderly (HYVET) trial. Age Ageing. 2013;42(2):253-258.

8. Mutasingwa DR, Ge H, Upshur RE. How applicable are clinical practice guidelines to elderly patients with comorbidities? Can Fam Physician. 2011;57(7):e253-e262.
9. Ghali JK, Kadakia S, Cooper R, Ferlinz J. Precipitating factors leading to decompensation of heart failure. Traits among urban blacks. Arch Intern Med. 1988;148(9):2013-2016.

10. Schäfer HH, Sudano I, Theus GR, Zilla P, Noll G, Burnier M. Blood pressure target attainment in the background of guidelines: the very elderly in Swiss primary care. Fam Pract. 2012;29(5):511-520.

11. Borzecki AM, Oliveria SA, Berlowitz DR. Barriers to hypertension control. Am Heart J. 2005;149(5):785-794.

12. Hajjar I, Miller K, Hirth V. Age-related bias in the management of hypertension: a national survey of physicians' opinions on hypertension in elderly adults. J Gerontol A Biol Sci Med Sci. 2002;57(8):M487-M491.

13. Rodriguez-Roca GC, Llisterri JL, Prieto-Diaz MA, et al. Blood pressure control and management of very elderly patients with hypertension in primary care settings in Spain. Hypertens Res. 2014;37(2):166-171.

14. James PA, Oparil S, Carter BL, et al. 2014 evidence-based guideline for the management of high blood pressure in adults: Report from the panel members appointed to the eighth joint national committee (JNC 8). JAMA. 2014;311(5):507-520.

15. Wood S. JNC 8 at Last! Guidelines Ease Up on BP Thresholds, Drug Choices. Heartwire. 2013. http://www.medscape.com/viewarticle/ 817991. Accessed February 17, 2014.

16. Sox HC. Assessing the trustworthiness of the guideline for management of high blood pressure in adults. JAMA. 2014;311(5):472-474.

17. Bauchner H, Fontanarosa PB, Golub RM. Updated guidelines for management of high blood pressure: recommendations, review, and responsibility. JAMA. 2014;311(5):477-478.

18. Peterson ED, Gaziano J, Greenland P. Recommendations for treating hypertension: What are the right goals and purposes? JAMA. 2013.

19. Weber MA, Schiffrin EL, White WB, et al. Clinical Practice Guidelines for the Management of Hypertension in the Community. The Journal of Clinical Hypertension. 2014;16(1):14-26.

20. Wood S. Hypertension Guidelines: But Wait, There's More. Heartwire. 2014. http://www.medscape.com/viewarticle/818652. Accessed February 17, 2014.

21. Go AS, Bauman M, King SMC, et al. An Effective Approach to High Blood Pressure Control: A Science Advisory From the American Heart Association, the American College of Cardiology, and the Centers for Disease Control and Prevention. Hypertension. Epub November 15, 2013.

22. O'Riordan M. AHA/ACC/CDC Issue 'Science Advisory' on Treating BP. Heartwire. 2013. http://content.onlinejacc.org/article. aspx?articleid=1778408. Accessed February 17, 2014.

23. Frieden TR, King S, Wright JS. Protocol-based treatment of hypertension: A critical step on the pathway to progress. JAMA. 2014; 311(1):21-22.

24. National Institute for Health and Clinical Excellence. NICE clinical guideline 127. Hypertension: clinical management of primary hypertension in adults. London: National Institute for Health and Clinical Excellence; 2011. Available from: http://www.nice.org. uk/nicemedia/live/13561/56008/56008.pdf. Accessed February 13, 2014.

25. Chobanian AV, Bakris GL, Black HR, et al. National Heart, Lung, and Blood Institute Joint National Committee on Prevention, Detection, Evaluation, and Treatment of High Blood Pressure; National High Blood Pressure Education Program Coordinating Committee. The Seventh Report of the Joint National Committee on Prevention, Detection, Evaluation, and Treatment of High Blood Pressure: the JNC 7 report. JAMA. 2003;289(19):2560-2572.

26. Houle SK, Padwal R, Tsuyuki RT. The 2012-2013 Canadian Hypertension Education Program (CHEP) guidelines for pharmacists: An update. Can Pharm J (Ott). 2013;146(3):146-150.

27. Kjeldsen SE, Julius S. Hypertension mega-trials with cardiovascular end points: effect of angiotensin-converting enzyme inhibitors and angiotensin receptor blockers. Am Heart J. 2004;148(5):747-754.

28. Briasoulis A, Agarwal V, Tousoulis D, Stefanadis C. Effects of antihypertensive treatment in patients over 65 years of age: a meta-analysis of randomised controlled studies. Heart. 2014;100(4):317-323. 
29. Banach M, Aronow WS. Hypertension therapy in the older adults-do we know the answers to all the questions? The status after publication of the ACCF/AHA 2011 expert consensus document on hypertension in the elderly. J Hum Hypertens. 2012;26(11):641-643.

30. Beckett NS, Peters R, Fletcher AE, et al; HYVET Study Group. Treatment of hypertension in patients 80 years of age or older. $N$ Engl J Med. 2008;358(18):1887-1898.

31. Bejan-Angoulvant T, Saadatian-Elahi M, Wright JM, et al. Treatment of hypertension in patients 80 years and older: the lower the better? A meta-analysis of randomized controlled trials. J Hypertens. 2010;28(7):1366-1372.

32. Reboldi G, Gentile G, Angeli F, Verdecchia P. Blood pressure lowering in the oldest old. J Hypertens. 2010;28(7):1373-1376.

33. Banach M, Aronow WS. Blood pressure j-curve: current concepts. Curr Hypertens Rep. 2012;14(6):556-566.

34. Panjrath GS, Chaudhari S, Messerli FH. The j-point phenomenon in aggressive therapy of hypertension: new insights. Curr Atheroscler Rep. 2012;14(2):124-129.

35. Chrysant SG. Current status of aggressive blood pressure control. World J Cardiol. 2011;3(3):65-71.

36. Pepine CJ, Handberg EM, Cooper-DeHoff RM, et al; INVEST Investigators. A calcium antagonist vs a non-calcium antagonist hypertension treatment strategy for patients with coronary artery disease. The International Verapamil-Trandolapril Study (INVEST): a randomized controlled trial. JAMA. 2003;290(21):2805-2816.

37. Denardo SJ, Gong Y, Nichols WW, et al. Blood pressure and outcomes in very old hypertensive coronary artery disease patients: an INVEST substudy. Am J Med. 2010;123(8):719-726.

38. Ogihara T, Matsuoka H, Rakugi H. Practitioner's trial on the efficacy of antihypertensive treatment in elderly patients with hypertension II (PATE-hypertension II study) in Japan. Geriatr Gerontol Int. 2011;11(4):414 421.

39. Hansson L, Zanchetti A, Carruthers SG, et al. Effects of intensive blood-pressure lowering and low-dose aspirin in patients with hypertension: principal results of the Hypertension Optimal Treatment (HOT) randomised trial. HOT Study Group. Lancet. 1998;351(9118):1755-1762.

40. Wake Forest Baptist Hospital. Systolic Blood Pressure Intervention Trial (SPRINT). Available form: http://clinicaltrials.gov/ct2/show/ NCT01206062NLM identifier: NCT01206062. Accessed November 2 , 2013.

41. Istituto Auxologico Italiano. European Society of Hypertension and Chinese Hypertension League Stroke in Hypertension Optimal Treatment Trial (ESH-CHL-SHOT). Available from: http://clinicaltrials.gov/ ct2/show/NCT01563731. NLM identifier: NCT01563731. Accessed November 2, 2013.

42. O'Brien E, Parati G, Stergiou G, et al; European Society of Hypertension Working Group on Blood Pressure Monitoring. European society of hypertension position paper on ambulatory blood pressure monitoring J Hypertens. 2013;31(9):1731-1768.

43. Sato I, Akazawa M. Polypharmacy and adverse drug reactions in Japanese elderly taking antihypertensives: a retrospective database study. Drug Healthc Patient Saf. 2013;5:143-150.

44. Law MR, Morris JK, Wald NJ. Use of blood pressure lowering drugs in the prevention of cardiovascular disease: meta-analysis of 147 randomised trials in the context of expectations from prospective epidemiological studies. BMJ. 2009;338:b1665.

45. Opiyo N, Shepperd S, Musila N, English M, Fretheim A. The "Child Health Evidence Week" and GRADE grid may aid transparency in the deliberative process of guideline development. J Clin Epidemiol. 2012;65(9):962-969.

46. Turnbull F, Neal B, Ninomiya T, et al. Blood Pressure Lowering Treatment Trialists' Collaboration. Effects of different regimens to lower blood pressure on major cardiovascular events in older and younger adults: meta-analysis of randomised trials. BMJ. 2008;336(7653):1121-1123.

47. Kjeldsen SE, Weber M, Oparil S, Jamerson KA. Combining RAAS and calcium channel blockade: ACCOMPLISH in perspective. Blood Press. 2008;17(5-6):260-269.
48. Duarte JD, Cooper-DeHoff RM. Mechanisms for blood pressure lowering and metabolic effects of thiazide and thiazide-like diuretics. Expert Rev Cardiovasc Ther. 2010;8(6):793-802.

49. Dhalla IA, Gomes T, Yao Z, et al. Chlorthalidone versus hydrochlorothiazide for the treatment of hypertension in older adults: a populationbased cohort study. Ann Intern Med. 2013;158(6):447-455.

50. Wehling M. Morbus diureticus in the elderly: epidemic overuse of a widely applied group of drugs. J Am Med Dir Assoc. 2013;14(6): $437-442$.

51. De Caterina AR, Leone AM. Why beta-blockers should not be used as first choice in uncomplicated hypertension. Am J Cardiol. 2010;105(10): 1433-1438.

52. Messerli FH, Grossman E, Goldbourt U. Are beta-blockers efficacious as first-line therapy for hypertension in the elderly? A systematic review. JAMA. 1998;279(23):1903-1907.

53. Fleg JL, Aronow WS, Frishman WH. Cardiovascular drug therapy in the elderly: benefits and challenges. Nat Rev Cardiol. 2011;8(1):13-28.

54. Wiysonge CS, Bradley HA, Volmink J, Mayosi BM, Mbewu A, Opie LH. Beta-blockers for hypertension [review]. Cochrane Database Syst Rev. 2012;11:CD002003.

55. Bangalore S, Sawhney S, Messerli FH. Relation of beta-blocker-induced heart rate lowering and cardioprotection in hypertension. $\mathrm{J} \mathrm{Am} \mathrm{Coll}$ Cardiol. 2008;52(18):1482-1489.

56. Costanzo P, Perrone-Filardi P, Petretta M, et al. Calcium channel blockers and cardiovascular outcomes: a meta-analysis of 175,634 patients. J Hypertens. 2009;27(6):1136-1151.

57. Coca A. Hypertension and vascular dementia in the elderly: the potential role of anti-hypertensive agents. Curr Med Res Opin. 2013;29(9):1045-1054.

58. Wang JG, Staessen JA, Li Y, et al. Carotid intima-media thickness and antihypertensive treatment: a meta-analysis of randomized controlled trials. Stroke. 2006;37(7):1933-1940.

59. Williams B, Lacy PS, Thom SM, et al; CAFE Investigators; AngloScandinavian Cardiac Outcomes Trial Investigators; CAFE Steering Committee and Writing Committee. Differential impact of blood pressure-lowering drugs on central aortic pressure and clinical outcomes: principal results of the Conduit Artery Function Evaluation (CAFE) study. Circulation. 2006;113(9):1213-1225.

60. Jamerson K, Weber MA, Bakris GL, et al; ACCOMPLISH Trial Investigators. Benazepril plus amlodipine or hydrochlorothiazide for hypertension in high-risk patients. $N$ Engl J Med. 2008;359(23): 2417-2428.

61. Chen GJ, Yang MS. The effects of calcium channel blockers in the prevention of stroke in adults with hypertension: a meta-analysis of data from 273,543 participants in 31 randomized controlled trials. PLoS One. 2013;8(3):e57854.

62. COLM Study Research Organization. Combination of OLMesartan and CCB or Low Dose Diuretics in High Risk Elderly Hypertensive Patients Study (COLM-Study). Available from: http://clinicaltrials. gov/show/NCT00454662. NLM identifier: NCT00454662. Accessed November 2, 2013.

63. Meurin P. The ASCOT trial: clarifying the role of ACE inhibition in the reduction of cardiovascular events in patients with hypertension. Am J Cardiovasc Drugs. 2006;6(5):327-334.

64. Hansson L, Lindholm LH, Ekbom T, et al. Randomised trial of old and new antihypertensive drugs in elderly patients: cardiovascular mortality and morbidity the Swedish Trial in Old Patients with Hypertension-2 study. Lancet. 1999;354(9192):1751-1756.

65. Yusuf S, Sleight P, Pogue J, Bosch J, Davies R, Dagenais G. Effects of an angiotensin-converting-enzyme inhibitor, ramipril, on cardiovascular events in high-risk patients. The Heart Outcomes Prevention Evaluation Study Investigators. $N$ Engl J Med. 2000;342(3):145-153.

66. Gosch M. The role of ACE inhibitors in the treatment of hypertensive elderly patients. Z Gerontol Geriatr. 2000;33(6):433-437.

67. Fretheim A, Odgaard-Jensen J, Brørs O, et al. Comparative effectiveness of antihypertensive medication for primary prevention of cardiovascular disease: systematic review and multiple treatments meta-analysis. $B M C$ Med. 2012;10:33. 
68. Fretheim A, Witter S, Lindahl AK, Olsen IT. Performance-based financing in low- and middle-income countries: still more questions than answers. Bull World Health Organ. 2012;90(8):559-559A.

69. Pappoe LS, Winkelmayer WC. ACE inhibitor and angiotensin II type 1 receptor antagonist therapies in elderly patients with diabetes mellitus: are they underutilized? Drugs Aging. 2010;27(2):87-94.

70. Levi Marpillat N, Macquin-Mavier I, Tropeano AI, Bachoud-Levi AC, Maison P. Antihypertensive classes, cognitive decline and incidence of dementia: a network meta-analysis. J Hypertens. 2013;31(6):1073-1082.

71. Weir MR, Rolfe M. Potassium homeostasis and renin-angiotensinaldosterone system inhibitors. Clin J Am Soc Nephrol. 2010;5(3): 531-548.

72. Dahlöf B, Devereux R, de Faire U, et al. The Losartan Intervention For Endpoint reduction (LIFE) in Hypertension study: rationale, design, and methods. The LIFE Study Group. Am J Hypertens. 1997;10(7 Pt 1): 705-713.

73. Mann J, Julius S. The Valsartan Antihypertensive Long-term Use Evaluation (VALUE) trial of cardiovascular events in hypertension. Rationale and design. Blood Press. 1998;7(3):176-183.

74. Lithell H, Hansson L, Skoog I, et al; SCOPE Study Group. The Study on Cognition and Prognosis in the Elderly (SCOPE): principal results of a randomized double-blind intervention trial. J Hypertens. 2003;21(5):875-886.

75. Boulanger JM, Hill MD. Morbidity and mortality after stroke--eprosartan compared with nitrendipine for secondary prevention: principal results of a prospective randomized controlled study (MOSES). Stroke. 2006;37(2):335-356; author reply 338 .

76. Carey RM, Logan AG. Acute candesartan cilexetil therapy in stroke survivors. Curr Hypertens Rep. 2004;6(2):114-116.

77. Cohn JN, Tognoni G; Valsartan Heart Failure Trial Investigators. A randomized trial of the angiotensin-receptor blocker valsartan in chronic heart failure. N Engl J Med. 2001;345(23):1667-1675.

78. Swedberg K, Pfeffer M, Granger C, et al. Candesartan in heart failure-assessment of reduction in mortality and morbidity (CHARM): rationale and design. Charm-Programme Investigators. $J$ Card Fail. 1999;5(3):276-282.

79. Makani H, Bangalore S, Desouza KA, Shah A, Messerli FH. Efficacy and safety of dual blockade of the renin-angiotensin system: meta-analysis of randomised trials. BMJ. 2013;346:f360.

80. van Vark LC, Bertrand M, Akkerhuis KM, et al. Angiotensinconverting enzyme inhibitors reduce mortality in hypertension: a meta-analysis of randomized clinical trials of renin-angiotensinaldosterone system inhibitors involving 158,998 patients. Eur Heart J. 2012;33(16):2088-2097.

81. Verdecchia P, Calvo C, Möckel V, Keeling L, Satlin A. Safety and efficacy of the oral direct renin inhibitor aliskiren in elderly patients with hypertension. Blood Press. 2007;16(6):381-391.

82. Duprez DA, Munger MA, Botha J, Keefe DL, Charney AN. Aliskiren for geriatric lowering of systolic hypertension: a randomized controlled trial. J Hum Hypertens. 2010;24(9):600-608.

83. Friedrich S, Schmieder RE. Review of direct renin inhibition by aliskiren. J Renin Angiotensin Aldosterone Syst. 2013;14(3):193-196.

84. McMurray JJ, Abraham WT, Dickstein K, Køber L, Massie BM, Krum H. Aliskiren, ALTITUDE, and the implications for ATMOSPHERE. Eur J Heart Fail. 2012;14(4):341-343.

85. Krum H, Massie B, Abraham WT, et al; ATMOSPHERE Investigators. Direct renin inhibition in addition to or as an alternative to angiotensin converting enzyme inhibition in patients with chronic systolic heart failure: rationale and design of the Aliskiren Trial to Minimize OutcomeS in Patients with HEart failuRE (ATMOSPHERE) study. Eur J Heart Fail. 2011;13(1):107-114.

86. ALLHAT Officers and Coordinators for the ALLHAT Collaborative Research Group. The Antihypertensive and Lipid-Lowering Treatment to Prevent Heart Attack Trial. Major outcomes in high-risk hypertensive patients randomized to angiotensin-converting enzyme inhibitor or calcium channel blocker vs diuretic: The Antihypertensive and LipidLowering Treatment to Prevent Heart Attack Trial (ALLHAT). JAMA. 2002;288(23):2981-2997.
87. Mancia G, Fagard R, Narkiewicz K, et al. Task Force Members. 2013 $\mathrm{ESH} / \mathrm{ESC}$ Guidelines for the management of arterial hypertension: the Task Force for the management of arterial hypertension of the European Society of Hypertension (ESH) and of the European Society of Cardiology (ESC). J Hypertens. 2013;31(7):1281-1357.

88. Vermeer SE, Longstreth WT, Koudstaal PJ. Silent brain infarcts: a systematic review. Lancet Neurol. 2007;6(7):611-619.

89. Ninomiya T, Ohara T, Hirakawa Y, et al. Midlife and late-life blood pressure and dementia in Japanese elderly: the Hisayama study. Hypertension. 2011;58(1):22-28.

90. Fletcher AE, Bulpitt CJ. How far should blood pressure be lowered? N Engl J Med. 1992;326(4):251-254.

91. Román GC, Tatemichi TK, Erkinjuntti T, et al. Vascular dementia: diagnostic criteria for research studies. Report of the NINDS-AIREN International Workshop. Neurology. 1993;43(2):250-260.

92. Chaudhry KN, Chavez P, Gasowski J, Grodzicki T, Messerli FH. Hypertension in the elderly: some practical considerations. Cleve Clin J Med. 2012;79(10):694-704.

93. Alpérovitch A, Blachier M, Soumaré A, et al. Blood pressure variability and risk of dementia in an elderly cohort, the Three-City Study. Alzheimers Dement. Epub 2013 August 14.

94. Morris MC, Scherr PA, Hebert LE, et al. Association between blood pressure and cognitive function in a biracial community population of older persons. Neuroepidemiology. 2002;21(3):123-130.

95. Ratnasabapathy Y, Lawes CM, Anderson CS. The Perindopril Protection Against Recurrent Stroke Study (PROGRESS): clinical implications for older patients with cerebrovascular disease. Drugs Aging. 2003;20(4):241-251.

96. Yamada K, Horita T, Takayama M, et al. Effect of a centrally active angiotensin converting enzyme inhibitor, perindopril, on cognitive performance in chronic cerebral hypo-perfusion rats. Brain Res. 2011; 1421:110-120.

97. Kishi T, Hirooka Y, Sunagawa K. Telmisartan reduces mortality and left ventricular hypertrophy with sympathoinhibition in rats with hypertension and heart failure. Am J Hypertens. 2014;27(2):260-267.

98. Gelber RP, Ross GW, Petrovitch H, Masaki KH, Launer LJ, White LR. Antihypertensive medication use and risk of cognitive impairment: the Honolulu-Asia Aging Study. Neurology. 2013;81(10):888-895.

99. Watfa G, Rossignol P, Kearney-Schwartz A, et al. Use of calcium channel blockers is associated with better cognitive performance in older hypertensive patients with subjective memory complaints. J Hypertens. 2010;28(12):2485-2493.

100. Denker MG, Cohen DL. What is an appropriate blood pressure goal for the elderly: review of recent studies and practical recommendations. Clin Interv Aging. 2013;8:1505-1517.

101. Bauer JH. Age-related changes in the renin-aldosterone system. Physiological effects and clinical implications. Drugs Aging. 1993; 3(3):238-245.

102. Monane M, Bohn RL, Gurwitz JH, Glynn RJ, Levin R, Avorn J. Compliance with antihypertensive therapy among elderly Medicaid enrollees: the roles of age, gender, and race. Am J Public Health. 1996;86(12):1805-1808.

103. Thoenes M, Spirk D, Böhm M, Mahfoud F, Thevathasan L, Bramlage P. Treatment of hypertension in the elderly: data from an international cohort of hypertensives treated by cardiologists. J Hum Hypertens. 2013;27(2):131-137.

104. Wang PS, Avorn J, Brookhart MA, et al. Effects of noncardiovascular comorbidities on antihypertensive use in elderly hypertensives. Hypertension. 2005;46(2):273-279.

105. Chrostowska M, Narkiewicz K. Improving patient compliance with hypertension treatment: mission possible? Curr Vasc Pharmacol. 2010;8(6):804-807.

106. LaFleur J, Oderda GM. Methods to measure patient compliance with medication regimens. J Pain Palliat Care Pharmacother. 2004;18(3): 81-87.

107. Claxton AJ, Cramer J, Pierce C. A systematic review of the associations between dose regimens and medication compliance. Clin Ther. 2001;23(8):1296-1310. 
108. Sherrill B, Halpern M, Khan S, Zhang J, Panjabi S. Single-pill vs freeequivalent combination therapies for hypertension: a meta-analysis of health care costs and adherence. J Clin Hypertens (Greenwich). 2011;13(12):898-909.

109. Hilleman DE, Ryschon KL, Mohiuddin SM, Wurdeman RL. Fixeddose combination vs monotherapy in hypertension: a meta-analysis evaluation. J Hum Hypertens. 1999;13(7):477-483.

110. Messerli FH, Oparil S, Feng Z. Comparison of efficacy and side effects of combination therapy of angiotensin-converting enzyme inhibitor (benazepril) with calcium antagonist (either nifedipine or amlodipine) versus high-dose calcium antagonist monotherapy for systemic hypertension. Am J Cardiol. 2000;86(11):1182-1187.

111. Hermann R, Rau M, Marx C, Wolf G. [Arterial hypertension: guideline acceptance and implementation in workaday life of internists and general practitioners in Thuringia]. Dtsch Med Wochenschr. 2013;138(25-26):1347-1352. German

112. Rizzo JA, Simons WR. Variations in compliance among hypertensive patients by drug class: implications for health care costs. Clin Ther. 1997;19(6):1446-1457; discussion 1424-1425.

113. Holt E, Joyce C, Dornelles A, et al. Sex differences in barriers to antihypertensive medication adherence: findings from the cohort study of medication adherence among older adults. J Am Geriatr Soc. 2013;61(4):558-564.

114. Chowdhury EK, Owen A, Krum H, et al. Second Australian National Blood Pressure Study Management Committee. Barriers to achieving blood pressure treatment targets in elderly hypertensive individuals. $J$ Hum Hypertens. 2013;27(9):545-551.
115. Volpe M, Battistoni A, Tocci G, et al. Cardiovascular risk assessment beyond Systemic Coronary Risk Estimation: a role for organ damage markers. J Hypertens. 2012;30(6):1056-1064.

116. Eggers KM, Venge P. Utility of B-type natriuretic peptides and cardiac troponins for population screening regarding cardiac abnormalities. Pathology. 2012;44(2):129-138.

117. Schäfer HH, Scheunert U. Costs of current antihypertensive therapy in Switzerland: an economic evaluation of 3,489 patients in primary care. Swiss Med Wkly. 2013;143:w13854.

118. Bramlage P, Hasford J. Blood pressure reduction, persistence and costs in the evaluation of antihypertensive drug treatment - a review. Cardiovasc Diabetol. 2009;8:18.

119. Ambrosioni E. Pharmacoeconomic challenges in disease management of hypertension. J Hypertens Suppl. 2001;19(3):S33-S40.

120. Schäfer HH, de Villiers JD, Sudano I, et al. Management of hypertension in patients with diabetes mellitus and metabolic syndrome in Swiss primary care. Int J Clin Pract. 2012;66(11):1125-1126.

121. Rochefort CM, Morlec J, Tamblyn RM. What differentiates primary care physicians who predominantly prescribe diuretics for treating mild to moderate hypertension from those who do not? A comparative qualitative study. BMC Fam Pract. 2012;13:9.

122. Grimm C, Köberlein J, Wiosna W, Kresimon J, Kiencke P, Rychlik R. New-onset diabetes and antihypertensive treatment. GMS Health Technol Assess. 2010;6:Doc03.
Clinical Interventions in Aging

\section{Publish your work in this journal}

Clinical Interventions in Aging is an international, peer-reviewed journal focusing on evidence-based reports on the value or lack thereof of treatments intended to prevent or delay the onset of maladaptive correlates of aging in human beings. This journal is indexed on PubMed Central, MedLine, the American Chemical Society's 'Chemical Abstracts Ser-

\section{Dovepress}

vice' (CAS), Scopus and the Elsevier Bibliographic databases. The manuscript management system is completely online and includes a very quick and fair peer-review system, which is all easy to use. Visit http://www.dovepress.com/testimonials.php to read real quotes from published authors. 